\title{
Atos Internacionais de Polícia Judiciária
}

\author{
Milton Fornazari JÚnior ${ }^{1}$
}

\section{INTRODUÇÃo}

A investigação criminal se desenvolve por meio da prática de atos ou de medidas de investigação, denominadas no Código de Processo Penal como diligências policiais ${ }^{2}$, as quais visam ao esclarecimento de fatos penalmente relevantes e à prova da materialidade e autoria de crimes, com a finalidade de viabilizar a responsabilização criminal de seus autores em juízo.

Além disso, no curso da investigação criminal, pode-se fazer necessária a apreciação pelo Poder Judiciário de medidas assecuratórias, como a prisão de investigados e/ou a indisponibilidade de bens e valores, sejam aqueles que constituam o instrumento ou objeto do crime, ou, ainda, outros visando a reparação do dano causado pelo ilícito penal.

Todas as diligências policiais desenvolvidas na investigação criminal devem ser necessariamente materializadas em um procedimento criminal, no caso da polícia judiciária, em um inquérito policial, presidido pelo Delegado de Polícia, em consonância com a vigência do Estado Democrático de Direito e do princípio do devido processo legal.

Obviamente, na hipótese de diligências policiais em andamento, deve-se aguardar o seu encerramento para posterior

1 Delegado de Polícia Federal, Professor da Escola Superior de Polícia e da Academia de Polícia Nacional, Doutor em Direito Processual Penal e Mestre em Direito Penal pela PUC/SP.

2 Artigo $5^{\underline{o}}$ e ss. do Código de Processo Penal. 
materialização nos autos do inquérito policial, a fim de não frustrar a consecução do ato.

No curso de uma investigação criminal, diante das provas e elementos de informação coligidos pelo Delegado de Polícia, pode surgir a necessidade da produção de provas e da adoção de medidas assecuratórias no exterior, além da prisão de um investigado também no exterior, principalmente nos crimes transnacionais.

Tal situação decorre do atual incremento da prática de crimes transnacionais, compreendidos como aqueles cuja preparação, execução ou resultado são repartidos em fases diversas, ocorrendo parte delas em um país e parte em outro.

Esses crimes são facilitados justamente pela nova ordem mundial, com a facilitação do trânsito de bens e pessoas entre os países, bem como com o uso dos avançados meios tecnológicos disponíveis.

Pela Convenção de Palermo (Decreto no ${ }^{\mathbf{0}}$ 5.015/2004), o conceito do crime transacional foi ampliado, restando configurado nas seguintes situações: a) quando cometido em mais de um Estado; b) quando cometido em um Estado, mas sua preparação foi substancialmente feita em outro; c) quando cometido em um Estado, mas a organização criminal do grupo é estabelecida em outro Estado ou d) quando embora cometido somente em um Estado, produziu efeitos substanciais em outro.

Para a realização desses atos de polícia judiciária, o Delegado de Polícia deve valer-se dos meios adequados de cooperação jurídica internacional previstos em lei e tratados internacionais. 


\section{Extradição Ativa}

Na hipótese de estarem presentes os requisitos da prisão preventiva do investigado, deverá o Delegado de Polícia representar em juízo pela decretação da medida, nos termos dos artigos 311 e 312 do Código de Processo Penal ${ }^{3}$.

Em razão da localização do investigado no exterior, além da decretação judicial da prisão preventiva, será necessário representar para que o juiz que decretou a prisão para que ele também determine a inclusão do nome do investigado na "difusão vermelha" da INTERPOL, a fim de que possa ele ser localizado e detido no país em que estiver.

A Organização Internacional de Polícia Criminal (INTERPOL) criada em Viena, em 1923, é um organismo internacional com personalidade jurídica própria, cuja finalidade é promover a cooperação policial internacional, inclusive nos casos em que não existam relações diplomáticas.Tem como princípio o caráter universal, portanto sem limitações territoriais, contando atualmente com 190 países-membros, sendo a segunda maior organização internacional intergovernamental existente, logo após a Organização das Nações Unidas (ONU), que conta com 192 países-membros. No Brasil ela é representada pela Polícia Federal.

3 “Art. 311. Em qualquer fase da investigação policial ou do processo penal, caberá a prisão preventiva decretada pelo juiz, de ofício, se no curso da ação penal, ou a requerimento do Ministério Público, do querelante ou do assistente, ou por representação da autoridade policial." "Art. 312. A prisão preventiva poderá ser decretada como garantia da ordem pública, da ordem econômica, por conveniência da instrução criminal, ou para assegurar a aplicação da lei penal, quando houver prova da existência do crime e indício suficiente de autoria. Parágrafo único. A prisão preventiva também poderá ser decretada em caso de descumprimento de qualquer das obrigações impostas por força de outras medidas cautelares (art. 282, § 40)." 
Por meio das forças policias que representam a Interpol nos respectivos países é que são concretizadas as prisões decorrentes da inclusão na referida "difusão vermelha".

Em seguida à efetivação da prisão no exterior, o juiz que deferiu a medida deverá solicitar a extradição do investigado para o Brasil.

A extradição é o mais antigo instituto de cooperação jurídica internacional e pode ser considerado o de natureza mais gravosa, por envolver diretamente a liberdade do indivíduo.

A extradição ativa, ou seja, quando o Brasil é o Estado requerente, é apresentada ao Estado requerido, observadas as cláusulas de tratado que eventualmente o Brasil tiver firmado com o Estado requerido, ou, na falta delas, os princípios da cortesia e da reciprocidade.

\section{Auxílio Direto em Matéria Penal}

Além da medida de prisão, que importa à liberdade de ir e vir do indivíduo, muitos são os exemplos de atos instrutórios do inquérito policial que deverão ser produzidos no exterior, visando o esclarecimento de fatos investigados no Brasil, tais como: a oitiva de uma testemunha que reside no exterior; a obtenção de documentos e extratos bancários de contas no exterior que comprovem atos de corrupção, evasão de divisas e/ou lavagem de dinheiro; a obtenção de documentos que certifiquem a propriedade de bens no exterior etc.

Por outro lado, em razão da possibilidade do desfazimento de bens e valores no exterior obtidos de maneira ilícita, se afigura necessária a realização no exterior de medidas cautelares que obtenham a decretação de indisponibilidade patrimonial pelas autoridades estrangeiras competentes. 
Assim, tanto para a promoção de atos tendentes a comprovar a materialidade e autoria de crimes, como para a concretização das medidas assecuratórias pertinentes, o Delegado de Polícia, obrigado legalmente a assim proceder $^{4}$, deve se valer do Auxílio Direto, meio de cooperação jurídica internacional previsto em diversos tratados internacionais devidamente incorporados ao ordenamento jurídico brasileiro.

A comunidade internacional reservou à extradição um regime mais gravoso, por importar a privação de liberdade do indivíduo.

Já em relação à obtenção de provas e promoção de medidas constritivas patrimoniais, o regime jurídico adotado para o auxílio direto é um pouco mais flexível, sem olvidar dos direitos e garantias fundamentais.

William C. Gilmore, ao analisar o "mutual legal assistance", no Brasil denominado como Auxílio Direto ${ }^{5}$, descreve que na última década do século passado houve um consenso mundial sobre as medidas que poderiam constituir o objeto do instituto, definindo-as por exclusão, como sendo todas aquelas que não se referem à detenção ou captura para fins de extradição, transferência de presos para cumprimento de decisões estrangeiras e transferência de procedimentos criminais. ${ }^{6}$

4 Art. 60 Logo que tiver conhecimento da prática da infração penal, a autoridade policial deverá (...) III - colher todas as provas que servirem para o esclarecimento do fato e suas circunstâncias;

5 “Art. 216-O. [...]. §2º do Regimento Interno do STJ: Os pedidos de cooperação jurídica internacional que tiverem por objeto atos que não ensejem juízo deliberatório do Superior Tribunal de Justiça, ainda que denominados de carta rogatória, serão encaminhados ou devolvidos ao Ministério da Justiça para as providências necessárias ao cumprimento por auxílio direto".

6 GILMORE, W.C. Mutual assistance in criminal and business regulatory matters, 1995. Cambrigde: Cambrigde University Press, p. Xii apud ABADE, Denise Neves. Direitos fundamentais na cooperação jurídica internacional: extradição, assistência jurídica, execução de sentença estrangeira e transferência de presos. São Paulo: Saraiva, 2013, p. 51. 
O auxílio direto em matéria penal, de acordo com seu regime jurídico no Brasil, constitui um instituto de direito público internacional e de direito processual penal, previsto em tratado internacional devidamente incorporado ao ordenamento jurídico interno, com status de lei ordinária, por meio do qual se estabelece o intercâmbio entre países acerca de documentos, provas, atos e medidas processuais constritivas patrimoniais, por intermédio de uma Autoridade Central ${ }^{7}$, incumbida da promoção da pretensão de um País, no interesse de uma investigação criminal ou de um processo penal no exterior (ativo) ou no Brasil (passivo).

De acordo com o autor português Manuel Antônio Lopes Rocha, o auxílio direto penal, lá chamado "auxílio judiciário geral", conceitua-se como:

É um conjunto de uma extensa série de atos de cooperação, como atos de processo penal de caráter instrutório, as informações sobre o direito estrangeiro e sobre os antecedentes penais, envio de documentos, objetos ou valores com interesse para a prova ou para a restituição aos lesados, e a cooperação em matéria de apreensão e perda dos produtos, objetos e instrumentos do crime. ${ }^{8}$

Foram assinados e promulgados no nosso ordenamento vinte tratados bilaterais que estabelecem o regime jurídico

7 A AUTORIDADE CENTRAL é figura típica do regime jurídico do mutual legal assistance. Trata-se de um órgão em cada país por meio do qual deve tramitar celeremente o auxílio direto, além de dispensar a necessidade da legalização consular para as informações e provas obtidas por meio do auxílio direto, tornando assim menos burocrática a cooperação jurídica internacional em matéria penal. No Brasil vigora o modelo executivo, assim como na Espanha, Inglaterra, Suécia, Suíça e Uruguai, dentre outros. Desta maneira, a autoridade central integra o Poder Executivo, trata-se do Departamento de Recuperação de Ativos e Cooperação Jurídica Internacional (DRCI), na Secretaria Nacional de Justiça, do Ministério da Justiça, criado administrativamente para essa finalidade. O Ministério Público Federal é a autoridade central no tratado com o Canadá e, também, na Convenção dos Países da Língua Portuguesa em Matéria Penal - CPLP, nesta última em conjunto com o DRCI/MJ.

8 ROCHA, Manuel Antonio Lopes; MARTINS, Teresa Alves. Cooperação judiciária internacional em matéria penal. Lisboa: aequitas e editorial Notícias, 1992, p. 14. 
standard do Auxílio Direto, com os seguintes países: Canadá (Decreto no 6.747/2009); China (Decreto nº 6.282/2007); Colômbia (Decreto $n^{\mathrm{o}} 3.895 / 2001$ ); Coréia do Sul (Decreto $n^{-0} 5.721 / 2006$ ); Cuba (Decreto n⿳0 6.462/2008); Espanha (Decretos n⿳0 6.681/2008 e $\mathrm{n}^{\mathrm{o}}$ 8.048/2013); Estados Unidos da América (Decreto $\mathrm{n}^{\mathrm{o}}$ 3.810/2001); França (Decreto no 3.324/1999); Honduras (Decreto no 8.046/2013); Itália (Decreto no 862/1993); México (Decreto $n^{\circ}$ 7.595/2011); Nigéria (Decreto no 7.582/2011); Panamá (Decreto no 7.596/2011); Paraguai (Decreto n⿳o 139/1995); Peru (Decreto no 3.988/2001); Portugal (Decreto no 1.320/1994); Reino Unido (Decreto $n^{\circ}$ 8.047/2013); Suíça (Decreto $n^{\circ}$ 6.974/2009); Suriname (Decreto nº 6.832/2009); e Ucrânia (Decreto no ${ }^{0}$ 5.984/2006).

Paralelamente, em virtude da especificidade do combate a cada espécie de crime transnacional, ou em razão do processo de integração regional do Mercosul, vários outros tratados internacionais multilaterais também foram assinados pelo Brasil.

Entre os mais importantes para o nosso estudo, devido à previsão do instituto do auxílio direto, estão os seguintes: “Convenção de Viena", ou Convenção contra o Tráfico Ilícito de Entorpecentes e Substâncias Psicotrópicas (Decreto nº 154/1991); Protocolo de Assistência Jurídica Mútua em Assuntos Penais no Mercosul (Decreto no 3.468/2000); "Convenção de Palermo", ou Convenção das Nações Unidas contra o Crime Organizado Transnacional (Decreto no 5.015/2004) 9; ; “Convenção de Mérida", ou Convenção das Nações Unidas contra a Corrupção (Decreto $n^{0}$ 5.687/2006); Convenção Interamericana sobre Assistência Mútua em Matéria Penal (Decreto nº 6.340/2008); e Convenção dos Países da Língua Portuguesa em Matéria Penal - CPLP (Decreto no 8.833/2016).

9 A Convenção de Palermo contra o crime organizado, ainda foi aditada por outros protocolos internacionais, referentes aos crimes de tráfico de pessoas (Decretos $\mathrm{n}^{\mathrm{o}}$ 5.016/2004 e nº 5.017/2004) e tráfico de armas (Decreto no 5.941/2006). 
Como podemos verificar, a grande maioria dos tratados internacionais sobre o auxílio direto foram criados após o ano 2000, o que demonstra a novidade do instituto no ordenamento jurídico brasileiro.

Por meio do auxílio direto, o País Requerente submete à apreciação estrangeira a solicitação da execução de determinado ato ou medida pelo órgão competente ou com atribuição legal no País Requerido, uma vez que há impossibilidade jurídica de atuação das autoridades brasileiras no País Requerido.

\section{De acordo com Gilson Langaro Dipp:}

Pelo pedido de auxílio jurídico direto, o Estado estrangeiro não se apresenta na condição de juiz, mas de administrador. Não encaminha uma decisão judicial a ser aqui executada, mas solicita assistência para que, no território nacional, sejam tomadas as providências necessárias à satisfação do pedido. Se as providências solicitadas no pedido de auxílio estrangeiro exigirem, conforme a lei brasileira, decisão judicial, deve a autoridade competente promover, na Justiça brasileira, as ações judiciais necessárias. O Estado estrangeiro, ao se submeter à alternativa do pedido de auxílio jurídico direto, concorda que a autoridade judiciária brasileira, quando a providência requerida exigir pronunciamento jurisdicional, analise o mérito das razões do pedido. O mesmo não ocorre no julgamento da carta rogatória pelo Superior Tribunal de Justiça, cujo sistema exequatur impede a revisão do mérito das razões da autoridade estrangeira, salvo para verificar violação à ordem pública e à soberania nacional. Na carta rogatória, dá-se eficácia a uma decisão judicial estrangeira, ainda que de natureza processual ou de mero expediente. No pedido de auxílio, busca-se produzir uma decisão judicial doméstica e, como tal, não sujeita ao juízo de delibação. ${ }^{10}$

10 DIPP, Gilson Langaro. Carta Rogatória e cooperação internacional. Revista CEJ, Brasília, Ano IX, nº 38, 2007, p. 39-43, em especial p. 40. 
Em relação à lei aplicável, vigora o princípio do locus regit actum, isto é, aplica-se a lei do local onde deva se produzir o ato pretendido pelo Estado requerente.

Ao optar pela cooperação por meio do auxílio direto, o País requerente concorda que a autoridade do País requerido efetue um juízo de mérito sobre o seu pedido, de acordo com a própria legislação interna, não se tratando de mero juízo de delibação, conforme ocorre com as cartas rogatórias.

Desta maneira, o País requerente não pode exigir a aplicação de sua lei ao País requerido, o que configuraria inegável afronta à soberania do país com o qual se pretende a cooperação por meio do auxílio direto.

\section{Os Atos e Medidas de Polícia Judiciária no EXTERIOR}

O objeto do auxílio direto segue delimitado em cada tratado, ora com alcance majorado, ora minorado, mas sempre limitado a questões que não se relacionem diretamente com a liberdade dos indivíduos, matéria afeta somente à extradição.

O artigo 18, item 3, da Convenção de Palermo ${ }^{11}$, delimita o objeto do auxílio direto, nos seguintes termos:

A cooperação judiciária prestada em aplicação do presente artigo pode ser solicitada para os seguintes efeitos:

a) recolher testemunhos ou depoimentos;

b) notificar atos judiciais;

c) efetuar buscas, apreensões e embargos;

d) examinar objetos e locais;

11 Convenção das Nações Unidas contra o Crime Organizado Transnacional (Decreto $\mathrm{n}^{\mathbf{0}}$ $5.015 / 2004)$. 
e) fornecer informações, elementos de prova e pareceres de peritos;

f) fornecer originais ou cópias certificadas de documentos e processos pertinentes, incluindo documentos administrativos, bancários, financeiros ou comerciais e documentos de empresas;

g) identificar ou localizar os produtos do crime, bens, instrumentos ou outros elementos para fins probatórios;

h) facilitar o comparecimento voluntário de pessoas no estado parte requerente;

i) prestar qualquer outro tipo de assistência compatível com o direito interno do estado requerido.

\section{O artigo 1ㅜㅜ, item 2, do Acordo Brasil e EUA, por sua vez, define o objeto de maneira similar:}

A assistência incluirá:

a) tomada de depoimentos ou declarações de pessoas;

b) fornecimento de documentos, registros e bens;

c) localização ou identificação de pessoas (físicas ou jurídicas) ou bens;

d) entrega de documentos;

e) transferência de pessoas sob custódia para prestar depoimentos ou outros fins;

f) execução de pedidos de busca e apreensão;

g) assistência em procedimentos relacionados a imobilização e confisco de bens, restituição, cobrança de multas; $e$ h) qualquer outra forma de assistência não proibida pelas leis do Estado requerido.

Na mesma linha é o Acordo entre Brasil e Suíça, cujo artigo $1^{\underline{0}}$, item 3 , dispõe que:

A cooperação jurídica abrange as seguintes medidas, tomadas em favor de um procedimento penal no Estado requerente: 
a) tomada de depoimentos ou outras declarações;

b) entrega de documentos, registros e elementos de prova, inclusive os de natureza administrativa, bancária, financeira, comercial e societária;

c) restituição de bens e valores;

d) troca de informações;

e) busca pessoal e domiciliar;

f) busca, apreensão, sequestro e confisco de produtos de delito;

g) intimação de atos processuais;

h) transferência temporária de pessoas detidas para fins de audiência ou acareação;

i) quaisquer outras medidas de cooperação compatíveis com os objetivos deste Tratado e que sejam aceitáveis pelos Estados Contratantes.

Conforme se verifica dos diversos tratados assinados pelo Brasil, as medidas que constituem o objeto do auxílio direto são praticamente as mesmas, podendo se afirmar que se referem a atos de instrução do inquérito policial ou do processo penal, além das medidas cautelares acessórias a esses procedimentos, próprios da persecução penal.

Portanto, caberá ao Delegado de Polícia no caso concreto identificar o ato ou medida de polícia judiciária cabível ao esclarecimento dos fatos investigados, elaborar a peça formal de auxílio direto e encaminhá-la à autoridade central brasileira.

A partir desse momento, a autoridade central fará a remessa do auxílio direto à sua congênere no País requerido, a qual ficará incumbida pela promoção do seu cumprimento junto às autoridades competentes no exterior. 
Uma vez chegado o auxílio direto no País requerido, o Delegado de Polícia deverá contar com o auxílio do adido policial brasileiro estabelecido no País requerido para contato com as autoridades locais, visando o melhor e mais eficaz cumprimento da medida solicitada.

\section{REFERÊNCIAS BibLIOGRÁFICAS}

ABADE, Denise Neves. Direitos fundamentais na cooperação jurídica internacional: extradição, assistência jurídica, execução de sentença estrangeira e transferência de presos. São Paulo: Saraiva, 2013.

ACCIOLY, Hildebrando; NASCIMENTO E SILVA, Geraldo E. e CASELLA, Paulo Borba. Manual de direito internacional público. 16 $6^{\mathrm{a}}$ ed. São Paulo: Saraiva, 2008.

AMBOS, Kai. Cooperação judiciária penal na Europa. Tradutor: José Paulo Baltazar Junior. In: BALTAZAR JUNIOR, José Paulo; LIMA Luciano Flores de. Cooperação jurídica internacional em matéria penal. Porto Alegre: Verbo Jurídico, 2010, pp. 477-510. . Prosecuting international crimes at the national and international level: between justice and real politique. In: KALECK, W; RATNER, M.; SINGELSTEIN, T. And Weiss p. (EDS.). International prosecution of human rights crimes - part II. Berlin, Heidelberg: Springer Verlag, 2007, p. 55-68.

ANSELMO, Marcio Adriano. Lavagem de dinheiro e cooperação jurídica internacional. São Paulo: Saraiva, 2013.

ARAS, Vladimir; LIMA Luciano Flores de. Cooperação penal direta pela Polícia ou Ministério Público. In: BALTAZAR 
JUNIOR, José Paulo; LIMA Luciano Flores de. Cooperação jurídica internacional em matéria penal. Porto Alegre: Verbo Jurídico, 2010, pp. 123-160.

ARAÚJO, Nádia de. A importância da cooperação jurídica internacional para a atuação do Estado brasileiro no plano interno e internacional. In: Manual de cooperação jurídica internacional e recuperação de ativos: cooperação em matéria penal. 2ª ed. Brasília: Ministério da Justiça, 2012, pp. 33-50.

. Cooperação Jurídica Internacional no Superior Tribunal de Justiça: Comentários à Resolução n⿳o 9/2005. Rio de Janeiro: Renovar, 2010.

Direito internacional privado: teoria e prática brasileira. $5^{\text {a }}$ ed. Rio de Janeiro: Renovar, 2011.

BALTAZAR JUNIOR, José Paulo; LIMA Luciano Flores de. Cooperação jurídica internacional em matéria penal. Porto Alegre: Verbo Jurídico, 2010.

CASTILHO, Ela Wiecko Volkmer de. Cooperação internacional da execução da pena: a transferência de presos. Revista Brasileira de Ci6encias Criminais. São Paulo, no 71, 2008, pp. 233-249.

CATELANI, Giulio. I Rapporti internazionali in materia penale: Estradizione, rogatorie, effetti delle sentenze penali straniere. Milano: Giuffrè, 1995.

CERVINI, Raúl; TAVARES, Juarez. Princípios de cooperação jurídica penal internacional no Protocolo do Mercosul. São Paulo: Revista dos Tribunais, 2000.

CIAMPI, Annalisa. L'Assunzione di prove all'estero in materia penale. Padova: Cedam, 2003.

COSTA, José de Faria; SILVA, Marco Antônio Marques da (coordenação). Direito Penal Especial, Processo Penal e 
Direitos Fundamentais: Visão Luso-Brasileira. São Paulo: Quartier Latin, 2006.

DIPP, Gilson Langaro. A cooperação jurídica internacional e o Superior Tribunal de Justiça: comentários à Resolução $n^{\underline{0}}$ 9/05. In: Manual de cooperação jurídica internacional e recuperação de ativos: cooperação em matéria penal. $2^{\mathrm{a}}$ ed. Brasília: Ministério da Justiça, 2012, pp. 29-31.

Carta Rogatória e cooperação internacional. Revista CEJ, Brasília, Ano IX, no 38, 2007, pp. 39-43.

FORNAZARI JUNOR, Milton. Cooperação Jurídica Internacional: Auxílio Direto Penal. São Paulo: Lumen Juris, 2016.

FRANCESCH, Joan Lluis Perez. Cooperación policial y judicial em la Convención de Prüm. Revista de derecho constitucional europeo, no 7, p. 119-136. Sevilla: Junta Del Andalucia, 2007.

FUX, Luiz. Homologação de sentença estrangeira. In: TIBURCIO, Carmen;

GARCIA, Rafael Arenas. Relaciones entre cooperación de autoridades y reconocimiento. In: Anuário español de derecho internacional privado. Barcelona: Iprolex, 2000, p. $231 / 260$

GILMORE, W.C. Mutual assistance in criminal and business regulatory matters. Cambrigde, Cambridge University Press, 1995.

GODOY, Luiz Roberto Ungaretti de. Crime organizado e seu tratamento jurídico penal. São Paulo: Elsevier, 2011.

LOULA, Maria Rosa Guimarães. Auxílio direto: novo instrumento de cooperação jurídica internacional civil. Belo Horizonte: Fórum, 2010. 
MACHADO, Maíra Rocha. Internacionalização do direito penal: a gestão de problemas internacionais por meio do crime e da pena. São Paulo: Ed. 34, 2004.

MADRUGA, Antenor. O Brasil e a jurisprudência do STF na idade média da cooperação jurídica internacional. Revista Brasileira de Ciências Criminais, ano 13, no 54. São Paulo: RT, 2005, p. 291-311.

McCLEAN, J.D. International Co-Operation in Civil and Criminal Matters. Londres: Oxford University Press, 2002.

MORO, Sérgio Fernando. Cooperação jurídica internacional em casos criminais: considerações gerais. In: BALTAZAR JUNIOR, José Paulo; LIMA Luciano Flores de. Cooperação jurídica internacional em matéria penal. Porto Alegre: Verbo Jurídico, 2010, pp. 14-58.

PAOLUCCI. Chiara Maria. Cooperazione giudiziaria e di polizia in materia penale. Torino: Utet Giuridica, 2011.

PEREIRA NETO, Pedro Barbosa. Cooperação penal internacional nos delitos econômicos. Revista Brasileira de Ciências Criminais, ano 13, no 54. São Paulo: RT, 2005, p. 153-168.

ROCHA, Manuel Antonio Lopes; MARTINS, Teresa Alves. Cooperação judiciária internacional em material penal. Lisboa: aequitas e Editorial Notícias, 1992, p. 14.

SAADI, Ricardo Andrade; BEZERRA, Camila Colares. $A$ autoridade central no exercício da cooperação internacional. In: Manual de cooperação jurídica internacional e recuperação de ativos: cooperação em matéria penal. $2^{\underline{a}}$ ed. Brasília: Ministério da Justiça, 2012, pp. 21-27.

SANCTIS, Fausto Martins de. Combate à Lavagem de Dinheiro: teoria e prática. Campinas: Millennium, 2008. 
SILVA, Marco Antônio Marques da. Acesso à Justiça Penal e Estado Democrático de Direito. São Paulo: Juarez de Oliveira, 2001.

SILVA, Ricardo Perlingeiro Mendes da Silva. Anotações sobre o anteprojeto de lei de cooperação jurídica internacional. Revista de Processo, ano 35, no 183. São Paulo: RT, 2005, pp. 133-168.

. Cooperação jurídica internacional e auxílio direto. Revista CEJ, Brasília, Ano IX, no 38, 2007, pp. 39-43.

SOUZA, Carolina Yumi de. Cooperação jurídica em matéria penal: considerações práticas. Revista Brasileira de Ciências Criminais, ano 16, no 71. São Paulo: RT, 2008, pp. 297-325.

SOUZA, Solange Mendes. Cooperação jurídica penal no Mercosul: novas possibilidades. Rio de Janeiro: Renovar, 2011.

STESSENS, Guy. Money Laudering: a new international Law Enforcment Model. Cambridge: Cambrigde University Press, 2000.

WEBER, Patricia Nuñez. A cooperação jurídica internacional em medidas processuais. Porto Alegre: Verbo Jurídico, 2011.

ZAVASCKI, Teori Albino. Cooperação jurídica internacional e concessão de exequatur. Revista de Processo, ano 35, no 183. São Paulo: RT, 2010, pp. 9-24. In Revista Brasileira de Ciências Criminais, vol. 37. São Paulo: RT, jan./mar. 2002. 